\title{
Por que o Brasil cresce pouco? Uma pergunta de tirar o sono
}

MENDES, Marcos. Por que o Brasil cresce pouco? Desigualdade, democracia e baixo crescimento no país do futuro. Rio de Janeiro: Elsevier; Campus, 2014.

Walter Marcos Knaesel Birkner

Centro Universitário Facvest (Unifacvest)

A pergunta de Marcos Mendes tira o sono de brasileiros, tanto quanto a leitura de seu livro "Por que o Brasil cresce pouco?" $\mathrm{O}$ autor integra um grupo de economistas do institucionalismo econômico, cujo esforço analítico ajudará o Brasil a encontrar o caminho do desenvolvimento nesse labirinto de regras e interesses, cujas falsas saídas apontam para a "inclusão populista", num cenário de rent seekings orientado pela lógica da "farinha pouca, meu pirão primeiro". O problema reside no dilema entre alta desigualdade e democracia, de onde o autor extrai a resposta decodificada em sua complexidade política e institucional, a partir da qual o Brasil finalmente saberá o caminho. Todavia, na bifurcação entre desenvolvimento e atraso, terá de acordar do sonho de "país do futuro" e espantar o pesadelo do descontrole fiscal, além de revisar a Constituição e promover a inclusão sustentável através de uma educação para a produtividade.

É um trabalho esclarecedor e bastante oportuno para compreender os fundamentos da crise brasileira, evidenciada em 2015 pelo grave problema fiscal que parece apontar para o esgotamento de um modelo de governar e sinaliza para os limites do welfare state quando dissociado da produtividade. Também ajuda a desmascarar a ficção de que os recursos estatais são ilimitados. Não obstante, quem espera encontrar um libelo antigovernista se frustra. Não é um conjunto de páginas a subsidiar o discurso contra o Estado, como alguns livros que compõem certa bibliografia dos meados da segunda década do século XXI, sinalizando a emergência de um conservadorismo liberal no Brasil, que ainda não se sabe se veio para ficar. Trata-se de um livro preocupado em apresentar, sem tergiversações, argumentos e diretrizes em prol de um combate definitivo à desigualdade, através da racionalidade no gasto público e de uma educação com foco na produtividade, sem o que um país nunca chega ao seu possível destino manifesto. 
De modo geral, a resposta ao baixo crescimento é dada a partir da equação entre alta desigualdade e democracia. Antes dela, reconhece o autor, o Brasil foi precedido por um regime autoritário, economicamente estatizado e protecionista que aprofundou o modelo de substituição de importações. Além disso, não teve o compromisso com a justiça social e com a educação dos mais pobres, resultando na "ampliação da desigualdade econômica". Com a democracia, construímos um cenário em que, embora tenha se tornado mais inclusivo, não realizamos o consenso nacional em torno dos quesitos para combater eficiente e permanentemente a desigualdade. Ao contrário, vimos a asseveração do conflito em que os segmentos sociais organizados procuram assegurar o seu quinhão através da aproximação com o Estado, reproduzindo, geração a geração, o patrimonialismo e o clientelismo nefastos, heranças de um passado que não quer passar.

Nessa perspectiva, a distribuição dos recursos no interior do sistema educacional brasileiro demonstra de maneira notável a desigualdade social perpetrada em nome de uma universalidade democrática que favorece os mais ricos. $\mathrm{Na}$ diferença entre o gasto com os estudantes das universidades públicas e do ensino fundamental e médio está um exemplo disso. O Brasil é "campeão" na desproporcionalidade em favor dos primeiros, sabendo-se que o ensino é gratuito e majoritariamente ocupado pelos mais ricos. Na equação do gasto público per capita para com esses estudantes, o Brasil apresenta o maior índice de desproporcionalidade, gastando 5,2 vezes mais com os alunos universitários, mais que o dobro do segundo colocado, a Índia. O Brasil gasta, com cada aluno de universidade pública, 93\% do PIB per capita, enquanto na Índia esse percentual é de 55\%, no México é de 35\%, na França é de 33\%, nos EUA é de 25\%, no Japão é de 19\%, no Chile é de 12\% e na Coréia é de 10\%. Os dados são de 2008 (p. 203).

Esse ambiente de alta desigualdade e democracia igualitarista seria propício a uma "disputa ineficiente por rendas entre diversos grupos", situação que, segundo o autor, conduz a um quadro de redistribuição dissipativa. Mendes reconhece que houve queda da desigualdade durante as três décadas de democracia pós-regime militar, mas ajuda a desmitificar a melhoria do bem estar e a inclusão como artifício exclusivo de governos. $\mathrm{Na}$ verdade, foi o aumento das commodities, das quais o Brasil e a América do Sul são grandes fornecedores, que provocou a inclusão de milhões de pessoas através de novas vagas de trabalho. $\mathrm{Na}$ direção contrária ao mito do bom governo, o livro nos revela antes como os gastos sociais do governo federal estão "concentrados em despesas como previdência social e remuneração do funcionalismo", que inibem a disponibilização de recursos públicos para ações que teriam maior potencial redistributivo.

E é nessa configuração política do Estado patrão que aparecem os rent seekings, que se organizam para assegurar a extração dos recursos estatais. Nas democracias igualitaristas em contextos de alta desigualdade de renda e patrimônio, por sua vez, surgem os rent seekings dos pobres, que essencialmente agem da mesma forma 
que os dos ricos, gerando demandas por um setor público cada vez maior (p. 23). Quanto maior o setor público, mais recursos o Estado precisa capturar da sociedade produtiva, o que resulta num modelo neopatrimonialista que o autor chama de baixo crescimento com redistribuição dissipativa. E o que se vê é um país sem adequada infraestrutura de transportes, energia e comunicações, sem escola de qualidade aos mais pobres, trabalhadores com baixa qualificação, barreiras ao comércio internacional, gasto público crescente sem retorno, sistema judicial emperrado, carga tributária elevada, taxa de juros alta, portos congestionados e, afinal, oportunidades perdidas.

$\mathrm{Na}$ seara de baixo crescimento e agudas disputas, a despesa corrente primária cresce de forma permanente. Conforme Mendes, "O setor industrial e os sindicatos, todavia, tem grande poder de influência e bloqueiam a liberalização das forças de mercado" (p. 55), sinalizando que o capital e o trabalho estejam, com alguma frequência, do mesmo lado e contra os interesses mais amplos da sociedade. Essa compreensão, que exige algum esforço interpretativo "desideologizado", desvela outro mito, tipicamente "progressista" de uma esquerda reacionária, segundo o qual o Estado seria o lócus exclusivo da representação dos interesses da burguesia. Isso já foi verdade. Não obstante, nas três décadas da democracia brasileira, aprendemos a ver que a esfera estatal, como em qualquer democracia, passa a ser ocupada por inúmeros outros segmentos da sociedade, desde sindicatos, corporações, associações e ONG, que compartilham o poder com os setores empresariais e a burocracia estatal.

Além disso, não se ignorem os milhões de eleitores pobres e as políticas assistenciais que os atendem. Nesse sentido, a desigualdade diminuiu com a incorporação de novos segmentos, conformando um quadro mais comprometido com a distribuição. Portanto, "ao longo de 30 anos de democracia, foi possível equilibrar as pressões políticas” (p. 78), aumentando o gasto público na medida em que se extrai, por meio de impostos, taxas e contribuições compulsórias, mais recursos da sociedade produtiva ${ }^{1}$. E, num contexto de poder legitimado pelo voto, políticos estão empenhados em atender as demandas da maioria de eleitores mais e mais exigentes pela prestação de serviços, ao tempo em que também são constrangidos pela força política dos prestadores desses serviços. Sobre isso, Mendes observa que "a busca do voto do eleitor mais pobre promove a expansão de programas sociais. Por outro (lado), um grupo de renda média-alta (os servidores públicos), em conexões com o poder governamental (...), consegue promover redistribuição de renda a seu favor" (p. 90).

Resultado disso, a economia fica sobrecarregada por tributação excessiva, infraestrutura ruim, educação precária, altas taxas de juros e ambiente de negócios inóspito. As perspectivas de crescimento de médio prazo empalideceram e esse

\footnotetext{
1 Ao fim dos oito anos de governo de Fernando Henrique Cardoso (1995-2003), a carga tributária havia aumentado de $26 \%$ para $36 \%$.
} 
quadro de paralisia produtiva ficou ainda mais visível a partir de 2015, ano subsequente ao livro "Por que o Brasil cresce pouco?". Depois de uma disputa eleitoral em que foi reeleito um governo marcado pela heterodoxia da "nova matriz econômica" que apostou na elevação dos gastos presentes pensando no retorno futuro e breve, o país entrou em recessão. $\mathrm{Na}$ lista dos problemas figuram os elementos apontados pelo autor: instabilidade fiscal, baixa produtividade, infraestrutura deficiente, baixa qualidade na educação e no ambiente de negócios. Isso tem levado analistas a sugerir o que está subentendido no livro de Mendes, ou seja, a "odiosa" ideia de que seja necessário o estabelecimento de um teto às despesas com o gasto público, como alternativa necessária à ameaça da "dominância fiscal".

Nessa direção, começamos a perceber o quanto nos falta, brasileiros, no executivo, no legislativo, no judiciário e sociedade em geral, a consideração devida do raciocínio econômico na promoção do desenvolvimento. Transferência de renda é sempre algo imediato e importante, sem dúvida, mas tem pouca relação com o desenvolvimento, que depende de soluções estruturais. A carga tributária excessiva, como qualquer brasileiro já deveria saber, inibe o crescimento, ao contrair o investimento e diminuir as taxas de lucro das empresas. Uma folha muito tributada dificulta a geração de novos empregos e novas empresas, ou estimula as empresas a se manterem pequenas. Enquanto, por exemplo, o custo de contratação trabalhista no Brasil é de 103\%, na França é de 80\%, na Inglaterra, de 59\%, na Itália, 51\%, no Japão 29\% e nos EUA, 9\%. Uma folha muito tributada é, assim, um dos sintomas de um país cujos governos inibem seu crescimento econômico e estimulam a evasão produtiva ${ }^{3}$.

Por essa razão, segundo o autor, as empresas brasileiras, em geral, são pequenas. Apenas nove por cento delas tem mais de dez funcionários. A tributação excessiva e uma legislação trabalhista da CLT de 1940, "excessivamente protecionista", as estimularia a se manterem pequenas ${ }^{4}$. Nesse sentido, também os salários ficam comprimidos no setor privado, fazendo com que a desigualdade de renda no mercado de trabalho privado seja a principal fonte da desigualdade no Brasil, responsável por $60 \%$ da composição do GINI, calculam Souza e Medeiros (Apud

\footnotetext{
${ }^{2}$ Segundo economistas, é quando a desordem das finanças foge do controle e torna ineficaz o efeito do aumento das taxas de juros sobre a inflação. Os juros altos tendem a piorar a situação, aumentando o valor da dívida, criando um quadro fiscal que impede o crescimento econômico por conta da dívida pública (http://economia.estadao.com.br/noticias/geral,dominanciafiscal, 1759259).

3 Notícias dão conta de um movimento de empresas brasileiras transferindo atividades produtivas para o Paraguai, a exemplo da matéria que aparece no link seguinte: http://jornaldesantacatarina.clicrbs.com.br/sc/noticia/2013/05/empresas-de-blumenau-eregiao-encontram-no-paraguai-saida-mais-competitiva-para-aumentar-a-producao.

${ }^{4}$ No Encontro Econômico Brasil - Alemanha 2015, de 20 a 22 de setembro, em Joinville-SC, empresários alemães em busca de parcerias com empresas de médio porte observaram ser proporcionalmente baixo o número de empresas desse porte no Brasil.
} 
p. 88). Aqui, finalmente, podemos substituir a velha e surrada explicação a respeito da "ganância do empresariado" como causa dos baixos salários. Aqui, o autor nos oferece uma instrutiva explicação fiscal, que deveria constar nos manuais de Sociologia do ensino médio brasileiro, num contraponto à conhecida perspectiva da expropriação do trabalho pelo capital.

Ora, nesse sentido, entende-se que os salários são baixos na iniciativa privada por conta dos encargos que, transferidos ao Estado, permitem a sustentação de melhores salários no setor público, como mostram estudos, a exemplo de Barbosa \& Barbosa Filho ${ }^{5}$. E são as altas remunerações de servidores públicos, além das altas aposentadorias e pensões, os outros dois fatores que praticamente totalizam a composição do índice de desigualdade nacional. Utilizando os dados da PNAD de 2003, Immervoll et al. mostram o caráter concentrador da previdência social no Brasil, revelando que $44 \%$ vão para $10 \%$ dos beneficiados; $71,5 \%$ dos benefícios estão nas mãos de $30 \%$. A previdência consome $11 \%$ do PIB e concentra mais da metade do gasto social, enquanto o Bolsa Família consome apenas 2,7\% desse gasto (Apud p. 99, p. 242). A previdência é desigual e, a continuar assim, sua dívida se tornará impagável. No setor público, há um milhão de beneficiados e a dívida anual é de $\mathrm{R} \$ 68$ mil per capita, enquanto na iniciativa privada seria de $\mathrm{R} \$$ $3.200,00$.

Nesse sentido, não há o que tergiversar: a principal e desejada característica de redução da desigualdade, sugere Mendes, será a diminuição da diferença entre os mais altos e os mais baixos salários. Assim, na perspectiva do autor, para continuar a reduzir a desigualdade daqui pra frente, "só se reduzir(mos) os benefícios mais elevados" (p. 95). Regras terão de ser alteradas, o que implica em mudanças institucionais que permitam o "pulo do gato". Algumas já foram, outras terão de vir, resultado de um jogo de forças cujo fortalecimento institucional na direção da justiça é pouco previsível, ante uma massa apedeuta sobre a relação entre as instituições e seus desejos de bem estar sustentável. Não obstante, pensando no longo prazo, insiste Mendes, somente com educação de qualidade e voltada às preocupações com o aumento da produtividade nacional será possível combater sustentavelmente a desigualdade.

Em situações de desigualdade, portanto, as instituições são fracas ou mal feitas. Mencionando Acemoglu e Robinson (2012), Mendes se refere às instituições econômicas extrativistas que travam o crescimento. Por exemplo, quando há concentração de poder e investimentos sob controle de pessoas que não são as mais eficazes e aptas, beneficiadas por suas relações com o poder e não pela

\footnotetext{
5 Em subcapítulo intitulado "A força política dos servidores públicos", Mendes menciona o trabalho de Ana Luiza de Holanda Barbosa e Fernando de Holanda Barbosa Filho, pelo IPEA (Texto para Discussão 1713), que demonstraria bem as diferenças salariais entre o serviço público e a iniciativa privada, as razões e as condições privilegiadas de quem está na primeira condição (apud p. 206).
} 
competência e mérito, isso resulta em baixa produtividade. Na desigualdade, a disputa dos rent seekings por riquezas já existentes impede ambientes propícios à produção de novas riquezas. Nesse cenário adverso, os ambientes são protecionistas e de baixa concorrência, sem estímulos à busca por produtividade. Ali, governos são controlados por patrimonialistas que transferem rendas a grupos privilegiados, fazendo com que a burocracia sirva não ao interesse público, mas em favor dos privilegiados, através de regras de benefícios, excluindo empresas e aniquilando oportunidades.

Nessa perspectiva, crescer só é (temporariamente) possível aumentando o gasto público, pilar da inflação, por sua vez, fator de aumento da desigualdade. Para Mendes, a estabilização promovida no Plano Real em 1995 foi a primeira causa da redistribuição duradoura, porque permitiu elevações de ganhos, protegidos pela moeda. Além disso, o autor reconhece a influência das aposentadorias rurais e dos programas sociais que foram implementados. Num interessante contraponto ao economista francês Thomas Piketty (2014), Mendes explica como os ricos aumentam suas rendas na inflação, porque se protegem por mecanismos bancários (p. 101). No primeiro decênio pós-regime militar (1985-1995) "o ímpeto redistributivo deu em hiperinflação, anulando a intenção redistributiva, concentrando ainda mais a renda dos mais ricos. $O$ que se redistribuiu, a inflação comeu". A partir do Plano Real, o autor demonstra graficamente que a renda dos mais ricos caiu notavelmente, demonstrando a relação entre inflação e desigualdade.

Mas aqui entra em cena o grão mestre dos rent seekings: o Estado. Mendes parece correto ao dizer que, comparados aos mais pobres, os mais ricos têm como se proteger da corrosão inflacionária. Não obstante, quem ganha com a inflação é o governo. E por quê? Por que quem deve e, arbitrariamente, paga quando quer como é o caso dos governos -, quanto mais atrasa, menos paga, na medida em que paga os valores nominais, ou sem a devida correção. E a história de governos fazerem caixa em tempos de inflação não é nova. Nessa direção, Piketty foi mais enfático, embora contrariando as críticas dos que, como Mendes, denunciam a inflação como fator de aumento da desigualdade. Nessa linha, o economista francês mostra como, em períodos inflacionários, os aplicadores perdem dinheiro e os pobres são beneficiados com transferências advindas dessas "sobras". Com todo o sentido que isso tenha, não se trata de um combate sustentável da desigualdade, significando no máximo uma temporária "inclusão populista".

Essa é uma boa briga teórica e tal debate acaba revelando uma interessante e crescente diferença de pensamento sobre política econômica entre grupos políticos programaticamente pouco distintos no Brasil. É em filigranas teóricas como essas que aparecem as tênues dessemelhanças programáticas entre, por exemplo, o Partido da Social Democracia Brasileira - PSDB e o Partido dos Trabalhadores - PT. Nas eleições gerais de 2014, no Brasil, o PSDB assumiu, pela primeira vez, a crítica ao gasto público desmedido e defendeu o protagonismo 
produtivo da sociedade. Com a natural limitação do vocabulário eleitoral, o PSDB procurou denunciar os efeitos enganosos do gasto público crescente defendido pelo governo do PT. Ainda que frágil e tímida ante as circunstâncias eleitorais, essa crítica ajudou a popularizar, no Brasil, a consciência sobre os limites do protagonismo estatal e de que não existe almoço grátis.

Assim, a contribuição de Mendes está em demonstrar que, quando regras permitem o abuso fiscal de governos, provocam distorções, constrangem o desenvolvimento e adiam o combate sustentável da desigualdade. O livro é útil ao mostrar como o Estado assume, paradoxalmente, o duplo protagonismo na condição de benfeitor e rent seeking. E, nesse ponto, Mendes vai à gênese e aponta para o "patriarca" dessa condição do Estado brasileiro: a Coroa portuguesa e suas instituições exemplares, como a proibição aos brasileiros de comercializar com outros países, as restrições ao livre cultivo, às autorizações e alvarás, à abertura de negócios, além de tributação excessiva, de empresas e pessoas ligadas aos governantes, que estiveram entre os primeiros movimentos dessa herança patrimonialista. Com a vinda da Coroa, a centralização é amplificada, resultando num vergonhoso sistema de regulação e privilégio, exposto na narrativa jurídicoantropológica de Raymundo Faoro no clássico "Os donos do poder".

O resultado político desse "modelo colonial extrativista" é uma classe poderosa ao redor do "centro do poder metropolitano," constituída de cortesãos e burocratas indicados pelo monarca, vivendo às custas da sociedade através do controle de todo esse emaranhado extrativista de constrangimentos legais e burocráticos. Normal em se tratando de sistemas monárquicos, mas anacrônico, para dizer o menos, em contextos republicanos. Para se ter uma ideia, trata-se do tipo de poder e de privilégios reais que, por exemplo, os senhores feudais da Inglaterra do século XIII começaram a eliminar a partir da Carta Magna de 1215, limitando o poder do rei, conhecido, por isso mesmo, como João "sem terras". Essencialmente - com o que concordam inúmeros autores e, também, Mendes -, é a partir dessas alterações institucionais que podemos compreender o destino virtuoso da Inglaterra e de outros países que se desenvolveram e se tornaram potências.

Assustadoramente, o Brasil que reconhecemos hoje é essencialmente o mesmo de Dom João VI. Dois séculos e sete cartas magnas depois, o eterno "país do futuro" mantém a essência patrimonialista e clientelista de suas origens e reproduz o modelo segundo a perspectiva de que é a sociedade dos indivíduos que serve ao poder central. Com toda a institucionalização e as lutas políticas até a Constituição cidadã de 1988, é constrangedor admitir que o Brasil mantenha as instituições extrativistas. Todas as gerações de elites emergentes, em nome dos interesses republicanos, não foram capazes de desarmar esse sistema centralizador que reproduz o velho "mercado de influência política e troca de favores" ao qual todos se veem obrigados a recorrer. Duzentos anos depois, a promiscuidade da busca de favores e a proteção faz acotovelarem-se entidades como "FIESP, ANFAVEA, 
FEBRABAN, entre outras", financiando campanhas com o mesmo intuito que comerciantes do passado compravam títulos da nobreza (p. 123).

Até hoje, como no passado imperial, boa parte de nossas instituições tem o mesmo sentido de manter fortes atilhos entre governo e agentes econômicos, fazendo com que o funcionamento da economia dependa do poder político, à revelia das leis do mercado. Nessa direção, nossos ciclos de crescimento são continuamente sucedidos por crises decorrentes da proteção, do subsídio e de endividamento futuro. Nossos voos são alçados com a outorga estatal, gerando anos de crescimento, seguidos de endividamento e baixo ou nulo crescimento. É precisamente o que constatamos na crise econômica brasileira deflagrada em 2015, produto da chamada "nova matriz econômica". Foram anos de incentivo ao consumo, de expansão do crédito, de gasto público excessivo, endividamento, juros altos, e, por fim, inflação alta e recessão. Mais um voo alçado pelo protagonismo estatal, mais um voo de galinha.

Esses ciclos se repetem, indefinidamente, porque não há "coincidência temporal entre causa e efeito", permitindo a sobrevivência, no tempo, dos discursos favoráveis a políticas econômicas inconsistentes. No amplo sistema de proteção ao capital nacional, ganham as empresas nacionais e seus empregados, perdem consumidores, contribuintes e a população em geral. Inúmeros e indiretos são os mecanismos protecionistas, de créditos e juros subsidiados, barreiras alfandegárias não tarifárias, preferência pelo produto nacional nas compras governamentais, entre outros, gerando ineficiência e aumento do gasto financiado pelo contribuinte. A força persistente disso reside no fato de que "mesmo os perdedores parecem convencidos de que são beneficiados". Não é que o protecionismo seja nossa exclusividade. O problema, segundo o autor, é sua conotação corporativa, favorecendo rent seekings privados e públicos, além do seu caráter permanente, retardando a competitividade da nossa economia "infante" no contexto da globalização (p. 156).

Marcos Mendes destaca que, apesar do viés de inclusão de nossa Carta Magna, ela continua, paradoxalmente, a permitir um peso redistributivo desproporcional aos ricos. Enquanto a redistribuição aos pobres é transparente, a dos ricos é protegida por sigilos bancários nos bancos públicos, por meio de serviços de difícil compreensão ao público em geral, como os benefícios já mencionados, entre inúmeros outros, justificados ideologicamente ou por alguma teoria econômica em defesa do suposto interesse nacional. Exemplo disso é o ensino universitário gratuito aos mais ricos, em nome do princípio da universalidade, fazendo do Brasil o país com o maior percentual de investimento per capita em alunos do ensino superior no Mundo, como já vimos, enquanto o percentual de pessoas com ensino superior continua abaixo dos 20\%, concluindo-o apenas $10 \%$ dos brasileiros (p. 203). 
De maneira geral, denuncia o autor, as concessões e privilégios do Estado brasileiro não são precedidos de cálculos sobre seus reais impactos. Bem no fim, essa tentativa de cada grupo manter rendas, que no fundo são extraídas de outros grupos, inviabiliza as "reformas que seriam favoráveis à maioria". Portanto, uma ampla reforma implicaria que certos grupos perderiam suas vantagens parciais. Grosso modo, esses grupos estão cientes disso, o que os faz preferirem deixar tudo como está. Nesse cenário egoístico e de insuficiência, as classes médias também entram no jogo. Exemplo é o caso da "meia entrada", engodo demagógico do governo, favorecendo estudantes subsidiados pelo contribuinte. Ali facilmente se chega à conclusão de como é patética a educação brasileira ao não ensinar noções elementares de matemática, segundo as quais é preciso saber de onde saem as benesses governamentais a beneficiados que fingem desconhecer o fato real de que alguém paga essa conta e esse alguém não é a "alta burguesia".

Por extensão, o grande problema apontado pelo autor é o fato de que a Constituição conferiu poderes extraordinários ao Judiciário, ao estabelecer a universalização de direitos. Nessas circunstâncias, se o Executivo não cumpre, o Judiciário faz cumprir, interferindo nas políticas públicas e na aplicação das leis. Promovido à condição de agente político, passa a controlar e arbitrar a vida dos cidadãos, que a ele recorrem o tempo todo como espaço para a solução de disputas e garantia dos direitos mais individuais, através de soluções judiciais. Ora, o problema passa a ser que, ao largo dessas garantias à manutenção de muitos interesses específicos, o sistema de distribuição "dissipativa" compromete a capacidade de gerar benefícios globais e atacar a desigualdade de modo sustentável.

Isso revela, afinal, que a universalização foi concebida sem correspondente definição das fontes de financiamento, resultando numa Constituição desproporcional ao PIB. Sendo incapaz de cumprir o que determina, ela reinstitui o cenário hobbesiano da luta de todos contra todos, produzindo o paradoxo de seu grande pressuposto: o combate à desigualdade. Como os grupos sociais mais informados tiram proveito jurídico para garantir seus direitos, a desigualdade se reproduz. Exemplo disso é que metade das crianças brasileiras vive abaixo da linha de pobreza, enquanto os idosos, em menor número, têm muito mais benefícios. Segundo Mendes, a média de transferências sem contrapartida para um idoso é 20 vezes maior do que às crianças, sendo que $45 \%$ delas são indigentes, contra $1,9 \%$ dos idosos (p. 65, p. 199). Diante disso, raciocina o autor, seria mais prudente aumentar o "Bolsa Família" do que consumir a maior parte dos recursos com os idosos. Fixando regras condizentes com a expectativa de vida e restringindo as aposentadorias especiais e outros privilégios, seria possível fazer justiça social.

Nessa direção, as últimas 50 páginas do livro "Por que o Brasil cresce pouco" constituem um dossiê estatístico a caracterizar a Constituição como um contrato de garantia à reprodução de "prejuízos coletivos e ganhos privados" a políticos, burocratas, servidores em geral e grupos de interesses. Trata-se de um libelo de 
casos exemplares de como esses grupos agem "garimpando ganhos nos meandros da lei", a exemplo dos servidores públicos e seus advogados que, o tempo todo, exploram regras legais a seu favor. $\mathrm{Na}$ intimidade com a esfera do poder e por meio da pressão dos sindicatos, servidores públicos reproduzem com desenvoltura e sem constrangimentos o toma lá dá cá, cujos exemplos mencionados no livro escandalizariam qualquer trabalhador da iniciativa privada, submetido à Consolidação das Leis do Trabalho - CLT.

A despeito disso, Mendes sugere que os anos de crescimento sustentado, de 1995 a 2010, teriam propiciado à sociedade brasileira o denominado "consenso de classe média”, de William Easterly (apud p. 234-235). Dessa forma, teríamos chegado à concordância coletiva sobre duas necessidades fundamentais, a saber: 1) a redução da desigualdade e 2) o equilíbrio fiscal, em superação à estratégia da "inclusão populista". No entanto, a recente desatenção ao segundo fator pôs em risco essa condição, num país em que $1 / 4$ da população recebe contracheques governamentais (apud VELLOSO; HAMILTON, 2013, p. 229). Em função da fragilidade fiscal, grande parte dos "ex-pobres" pode acabar voltando à vulnerabilidade social e teremos perdido a nossa capacidade de combate à pobreza, uma vez que o Estado brasileiro, segundo Mendes, esgotou sua capacidade de aumentar o gasto público para a inclusão.

À luz de mais um fracasso governamental e na expectativa de anos de recessão, livros como o do economista Marcos Mendes ajudam o público leigo a compreender os limites do Estado patrimonialista e centralizador, ao qual todos recorrem, por foça das circunstâncias institucionais, em busca do seu quinhão. $\mathrm{Na}$ extensão disso, revela-se o mérito teórico da obra do autor, ao mostrar como o Estado democrático e de direito pode nos tornar ainda mais egoístas. Envoltos no ambiente constitucional neo-hobbesiano, os caçadores de rendas reforçam a lógica do "cada um por si e o Estado por todos". A constatação disso faz o leitor compreender como as instituições influenciam os comportamentos e a cultura de indivíduos e organizações. Nessa direção, a difusão do institucionalismo econômico, para além do campo dos especialistas, ajudará brasileiros a perceberem que a raiz do problema econômico das nações é político e é solucionável, desde que haja clareza e vontade política.

Por decorrência, o que aprendemos com as leituras da crise é que o desenvolvimento não é uma quimera e se torna viável por meio das reformas do Estado. Previdência, leis, protecionismo, isolamento comercial, gasto incontrolável, educação dissociada da produtividade, tudo se soma à necessidade de uma revisão constitucional, que começaria mesmo antes, com o estabelecimento de um padrão fiscal sustentável, ao arrepio dos "desenvolvimentistas". Para além disso, a leitura de Mendes nos impele a reconhecer que a relação entre Estado e sociedade precisa ser alterada na direção do equilíbrio e, talvez, lá na frente, da inversão no protagonismo. Embora pareça utópico, não é. O "ponto de mutação" exige a assunção de um novo conjunto de 
ideias, pautadas na autonomia, na liberdade, no risco e na independência, com tudo que termos como esses têm de redundância, mas também de complementariedade.

Essas ideias, harmonicamente vinculadas à preocupação estratégica com a produtividade nacional, poderão ajudar a reorganizar o sistema educacional do país. E então já não haverá mistério: além do que aprendemos com Mendes acerca do uso correto dos recursos produzidos, o combate efetivo à desigualdade dependerá de "educação de qualidade". Embora recorra ao bordão linguístico, o autor elucida as vantagens disso, demonstrando a expansão do ensino básico durante a redemocratização e seus benefícios aos mais pobres. Para se ter ideia, em 1980 havia 20\% das crianças de 7 a 14 anos fora da escola. Em 2009, o ensino fundamental estava praticamente universalizado. O livro mostra por estatística que esforço semelhante no ensino médio teve o relevante efeito de diminuir a desigualdade e aumentar a produtividade nacional (p. 74, p. 171-172). Por outro lado, como já vimos, o ensino universitário permanece voltado à elite do país, tornando questionável um alto gasto público que distancia os mais carentes dos privilegiados.

Não obstante, é a correta preocupação com a produtividade que mais chama à atenção. É a educação, ou o capital humano, como enfatiza o autor, "uma potente ferramenta para colocar um país na rota do desenvolvimento". E continua afirmando que "a principal ligação entre educação e crescimento é o aumento da produtividade" (p. 73). Não obstante, nesse contexto de democracia e alta desigualdade, será preciso desfazer as armadilhas criadas e constitucionalmente respaldadas, como, por exemplo, a que faz do Brasil o país que mais gasta no mundo com alunos do ensino superior, comparado ao gasto com o ensino fundamental e médio. São exemplos que confirmam a tese do autor sobre o modelo brasileiro que associa democracia com alta desigualdade e baixo crescimento com redistribuição dissipativa. Com a leitura do livro de Marcos Mendes aprende-se muito, e de maneira clara, sobre a importância teórica do institucionalismo para compreender como as regras influenciam comportamentos e afetam o desenvolvimento nacional, permitindo ao leitor entender, afinal, porque o Brasil cresce pouco.

\section{Referências}

ACEMOGLU, Daron; ROBINSON, James. Por que as nações fracassam? As origens do poder, da prosperidade e da riqueza. Trad. Cristiana Serra. Rio, Elsevier; Campus, 2012.

BIRKNER, Walter M. K. O capital no século XXI (resenha). Desenvolvimento em Questão, 13 (32), p. 334-43, set., 2015. 
MENDES, Marcos. Por que o Brasil cresce pouco? Desigualdade, democracia e baixo crescimento no país do futuro. Rio de Janeiro: Elsevier; Campus, 2014.

PIKETTY, Thomas. O capital no século XXI. Trad. Monica Baumgarten de Bolle. Rio de Janeiro: Intrínseca, 2014.

O GLOBO. Apenas 10\% dos brasileiros terminam o ensino superior. O Globo. Rio de Janeiro, 08.09.2009 < http://oglobo.globo.com/sociedade/educacao/ apenas-10-dos-brasileiros-terminam-ensino-superior-3210787>.

Endereço para correspondência:

Walter Marcos Knaesel Birkner - b-walter@hotmail.com

Rua Bento Gonçalves, 784, Bairro Armação

88.835-000 Penha/SC, Brasil 